https://helda.helsinki.fi

Nganasan - a fresh focus on a little known Arctic language

\author{
Janhunen, Juha
}

2020-05

Janhunen , J \& Gruzdeva , E 2020 , ' Nganasan - a fresh focus on a little known Arctic

language ' , Linguistic Typology , vol. 24 , no. 1 , pp. 181-186 . https://doi.org/10.1515/lingty-2020-2036

http://hdl.handle.net/10138/318080

https://doi.org/10.1515/lingty-2020-2036

submittedVersion

Downloaded from Helda, University of Helsinki institutional repository.

This is an electronic reprint of the original article.

This reprint may differ from the original in pagination and typographic detail.

Please cite the original version. 


\title{
Nganasan —a fresh focus on a little known Arctic language
}

\author{
Juha Janhunen \& Ekaterina Gruzdeva
}

\section{Reviewed publication:}

Beáta Wagner-Nagy. A Grammar of Nganasan. (Grammars and Language Sketches of the World's Languages: Indigenous Languages of Russia.) Leiden: Brill, 2018. xviii, 583 pp. ISBN 978-90-04-38275-6 (hardback), 978-90-04-38276-3 (e-book).

Nganasan is a language of considerable interest for both Uralic studies and general linguistic typology. Spoken on Taimyr Peninsula in Arctic Siberia, it is not only the easternmost surviving Uralic language, but also the northernmost language of Eurasia, and even globally second only to some varieties of Inuit. Conventionally classified as a member of the "northern" group of Samoyedic, it is more correctly understood as representing the first offshoot of Proto-Samoyedic, which started moving northward along the Yenisei some two millennia ago and reached Taimyr at least several centuries ago. Nganasan retains some archaic lexical and grammatical features replaced by secondary innovations shared by all the other Samoyedic languages. At the same time, due to its geographical location it probably includes a substantial amount of relatively recent substrate material from the subsequently lost languages spoken previously on Taimyr.

Historically, the Nganasan-speaking communities used to maintain an archaic subsistence economy based on wild reindeer hunting, supplemented by fishing and gathering. The size of the speech community has probably always been at the range of a few hundred individuals, reaching the peak of approximately a thousand in the early 20th century. During the Soviet period, whose effects became felt on Taimyr only in the 1930s, the traditional lifestyle was replaced by "modern" solutions, which included the introduction of reindeer herding and the forced settlement of the originally nomadic population in permanent villages. Combined with the system of boarding schools, these changes have led to the rapid decline of the ethnic language, with hardly more than 100 elderly and middle-aged speakers surviving today, and with virtually no children fluent in Nganasan.

Typologically, Nganasan remains in many respects a typical Uralic and Samoyedic language, with features such as head-final word order (SOV and GAN), suffixally marked inflectional and derivational morphology, including three numbers (unmarked singular plus marked dual and plural), a relatively elaborate system of three grammatical cases (unmarked nominative plus marked accusative and genitive, in the modern language merged into a uniform connective), four local cases (dative, locative, ablative, prosecutive), and one secondary modal case (comitative), a rich system of verbal forms (expressing aspect, tense, nominalization, converbialization, etc.), as well as personal marking on nouns (predication and possession) and verbs (subjective, objective and reflexive predication). What makes Nganasan stand out in the Uralic and Samoyedic context is its exceptionally complicated morphophonology, with stem-final vowel and consonant alternations, stem-internal and suffix-initial consonant gradation, as well as a peculiar type of vowel harmony, which only distantly preserves a trace of the original palatal-velar oppositions.

The grammar of Nganasan by Beáta Wagner-Nagy is not only the first grammar of the language in English, but also the most comprehensive description of Nganasan so far. It would, however, be a mistake to think that Nganasan was an undescribed language before the 
publication of this grammar, for the language was well documented already in the mid 19th century by M. A. Castrén (1854). A standard reference grammar was published in Russian by N. M. Tereshchenko forty years ago (1979), and there is also an excellent grammatical synopsis in English by Eugene Helimski (1998). A massive compilation of texts and grammatical material, based largely on the field work of Kazis I. Labanauskas, was published by Michael Katzschmann (2008). Among the previous works of Wagner-Nagy herself we find a monograph on Nganasan word formation (2001). In collaboration with Zsuzsa Varnai and Sándor Szeverényi she edited a "Nganasan chrestomathy" in Hungarian (2002), containing a grammatical description with accompanying texts and glossary.

The new grammar is organized in 17 chapters, which in addition to the (1) introduction and (17) text samples, discuss various aspects of the language in the following order: (2) phonetics and phonology, (3) word classes, (4) nominal inflection, (5) verbal inflection, (6) evidentiality, (7) verbal valency, (8) noun phrase, (9) types of predicate, (10) simple sentences, (11) ditransitive constructions, (12) negation, (13) clause combining, (14) discourse organization, (15) lexicon, and (16) word formation. As may be seen, the grammar takes up several "modern" topics, including valency, transitivity and evidentiality, which have not been dealt with systematically in earlier descriptions of Nganasan. A new feature of the work is also that it is based on a corpus comprising some 21,000 sentences, based partly on the collections of Wagner-Nagy herself and her immediate colleagues, but partly also on the results of earlier fieldwork by others. The material comes from altogether 34 informants, whose years of birth range from 1905 to 1958.

If we evaluate the merits of this grammar in terms of the traditional division between phonology, morphology, and syntax, it is clearly syntax that is its greatest contribution. This is also the part that most immediately reflects the personal contribution of Beáta WagnerNagy herself, for Nganasan morphology, especially inflectional morphology, was comprehensively described already by Castrén, and some of the forms that he recorded are already impossible to elicit from the modern speakers. Phonology, on the other hand, is clearly not a strong side of Wagner-Nagy, and the phonological discussion in the new grammar is largely based on the earlier work of Zsuzsa Várnai, which, unfortunately, also involves problems. The problems concern both the analysis of the segmental system and the notation used for transcribing Nganasan.

Tundra Nenets is so far the only Samoyedic language for which an adequate phonological notation has been developed — by Tapani Salminen (1997) — and it would be high time to create similarly adequate systems for the other Samoyedic languages, including Nganasan. Unfortunately, modern works on Nganasan, including even those by Eugene Helimski, have opted for using an unsystematic mixture of phonetic and phonemic notation, with graphically complex and mutually contradictory symbols. For instance, it is totally unnecessary to distinguish notationally the intervocalic spirant [ð] and the postnasal voiced stop [d], as they represent allophones of a single phoneme that could easily be rendered as /d/. It is also a misleading convention to use the notation $<\mathrm{d}$ ' $>$ for what is a voiced palatal stop [[J] or affricate [ $\mathrm{d}]$, when the simple /j/ would have been available - the more so as this segment can be pronounced in some varieties of the language as [j]. It happens that the same phoneme appears in syllable-final position with the phonetic value [j], in which case Wagner-Nagy (following Várnai) uses the notation $\langle\mathrm{j}>$.

The Nganasan vowel system offers many unsolved problems. One problem is connected with the fact that apart from a somewhat asymmetrical system of 8 simple monophtongs, Nganasan 
has bimoraic long vowels and vowel sequences, some of which are of a Proto-Samoyedic origin, as well as two monomoraic "diphthongs", which Wagner-Nagy renders as [ia] and [ua], but which could more properly be rendered by monosegmental symbols like [ä] and [å], respectively, especially as they are actually often pronounced as monophthongs. With these additions, the system of simple vowels would look more symmetrical: there would be three unrounded back vowels /a ë i//, three rounded back vowels /å o u/, three unrounded front vowels /ä e i/, and one lonely high rounded front vowel /ü/. There are also many phenomena connected with the interaction of the individual vowel qualities with adjacent consonants. Without going into further details we may say that Nganasan phonology is a complicated field, and it has not been fully described in the new grammar.

It is much better when it comes to the morphosyntactic analysis. Unlike previous treatments of Nganasan, the new grammar is certainly "typology-friendly", in the sense that it presents the data in a way that can be used by general linguists and typologists — for whom phonemic precision is often of little relevance. The author is well oriented in contemporary linguistic theory and terminology, though in some cases it would have been helpful to explain more precisely how and why a specific term is used. The grammatical analysis is for the most part clear and is obviously based on the existing typological descriptions of particular linguistic categories. As is mentioned in the introduction, the grammar has "a traditional structure", which means that it consistently moves from nominal to verbal categories and from phrasal level via simple and complex sentences to discourse structure. Also, the analysis of the data proceeds in some cases from function to form, but more often from form to function. Such an approach is justified for a reference grammar, whose goal is the comprehensive description of a particular language, though it can be challenged by general typologists seeking for a unified description of functional categories.

In general, the distribution of data across various chapters and sections works well, but in several cases the decisions made by the author raise questions. As might be expected, certain difficulties are created by the strict differentiation between inflection (chapters 4 and 5) and word formation (chapter 16). This applies, in particular, to verbal categories and especially to aspect. Aspect is initially (in section 5.2) analysed as an inflectional category, a decision that itself is rather questionable since the forms examined in this section are either inherently perfective/imperfective or acquire the one or the other aspectual meaning through derivation, and not by inflection. Later (in section 16.6.3.2.3), aspect is surveyed again, and this time only as a derivational category. As a result, the overall status of aspect in Nganasan remains unclear, though it is evident that the question is not about inflection, but about an interplay between lexical and grammatical aspect. In a similarly inconsistent way transitivization and causativization are treated first as valence-changing operations (in section 7.2) and later as derivational processes (in section 16.6.3.2.2).

Following current typological trends, the author has chosen to devote a separate chapter (6) to the semantic-functional domain of evidentiality and its grammatical markers. Nganasan differentiates both direct and indirect evidential meanings. Interestingly, direct evidentiality in Nganasan is marked only if it is based on auditive or sensitive sensation, whereas direct visual sensation is unmarked. Indirect evidentiality is less atypical and distinguishes two subtypes, viz. inferred and reported evidentiality. The former is linked to mirativity, which involves the marking of information as new and unexpected. Evidential markers, such as verbal mood suffixes, particles, nominalized and adverbialized forms are described in other chapters of the grammar as well, so the "evidential" chapter stands out from other parts of the grammar in that it is purely functionally driven. Typologists would probably advocate a similar approach 
to the description of other functional domains of the language.

Another largely typologically oriented chapter (12) is devoted to negation in Nganasan. This chapter is obviously based on the author's previous work on negation in Uralic languages (Wagner-Nagy 2011, Miestamo, Tamm and Wagner-Nagy 2015). Here, Wagner-Nagy discusses the means of marking constituent and clause negation, including standard negation and negation in existential, possessive, locative, purposive and prohibitive clauses. The chapter covers all essential semantic and grammatical topics pertaining to negation and describes in detail the behaviour and inflection of the negation markers. As in several other Samoyedic and Uralic languages (and already in Proto-Uralic), standard negation is expressed by a fully conjugated negation verb, combined with an invariant "connegative" form of the semantic head verb. More idiosyncratically, existential negation is in Nganasan expressed by a separate negator, which Wagner-Nagy identifies as a "negative particle", but which is actually a negative existential noun - a strategy well known from, for instance the Turkic and Mongolic languages. In general, the chapter on negation is informative, but a critical remark could be made about the terms "sentence negation" and "clause negation", which are used in this section as synonyms without any further discussion.

In conclusion it may be said that the Nganasan grammar by Beáta Wagner-Nagy succeeds in filling a gap in linguistic literature. Its reader-friendliness is enhanced by a clear layout and the presence of a map, some 80 tables and figures, as well as a detailed index. Unfortunately, as has already been noted by Larisa Leisiö (2019) in her review of this same volume, there are relatively many misprints, notational and terminological inconsistencies, and even cases of misanalysis. A more careful final editing of the text could easily have removed these problems. Even so, there is no doubt that this grammar will remain the basic tool through which the severely endangered and typologically challenging Nganasan language has finally become accessible to the international community of general linguists.

\section{References}

Castrén, M. A. 1854. Grammatik der samojedischen Sprachen. (Nordische Reisen und Forschungen 7.) Herausgegeben von Anton Schiefner. St. Petersburg: Kaiserliche Akademie der Wissenschaften.

Helimski, Eugene. 1998. Nganasan. In: Daniel Abondolo (ed.), The Uralic Languages.

(Routledge Language Family Descriptions.) London: Routledge. 480-515.

Katschmann, Michael. 2008. Chrestomathia Nganasanica: Texte-Übersetzung-GlossarGrammatik. (Nganasanica 1.) Norderstedt: Books on Demand GmbH.

Leisiö, Larisa. 2019. A first but not the definitive grammar of Nganasan. International Journal of Eurasian Linguistics 1/1: 229-236.

Miestamo, Matti, Anne Tamm and Beáta Wagner-Nagy (eds.). 2015. Negation in Uralic Languages. (Typological Studies in Language 108.) Amsterdam: John Benjamins.

Salminen, Tapani. 1997. Tundra Nenets Inflection. (Mémoires de la Société Finno-Ougrienne 227.) Helsinki: Finno-Ugrian Society.

Tereščenko, N. M. 1979. Nganasanskii iazyk [The Nganasan language]. Leningrad: Nauka.

Wagner-Nagy, Beáta. 2001. Die Wortbildung im Nganasanischen. (Studia Uralo-Altaica 43.) Szeged: University of Szeged, Department of Finno-Ugric Studies.

Wagner-Nagy, Beáta (ed.). 2002. Chrestomathia Nganasanica. (Studia Uralo-Altaica 10 Supplementum.) Szeged: SZTE Finnugor tanszék — Budapest: MTA Nyelvtudományi intézet. 
Wagner-Nagy, Beáta. 2011. On the Typology of Negation in Ob-Ugric and Samoyedic

Languages. (Mémoires de la Société Finno-Ougrienne 262.) Helsinki: FinnoUgrian Society.

Juha Janhunen

asiemajeure@yahoo.com

University of Helsinki

Ekaterina Gruzdeva

ekaterina.gruzdeva@helsinki.fi

University of Helsinki 